\title{
Corrigendum: Investigating the relationship between corporate social responsibility and market, cost and environmental performance for sustainable business
}

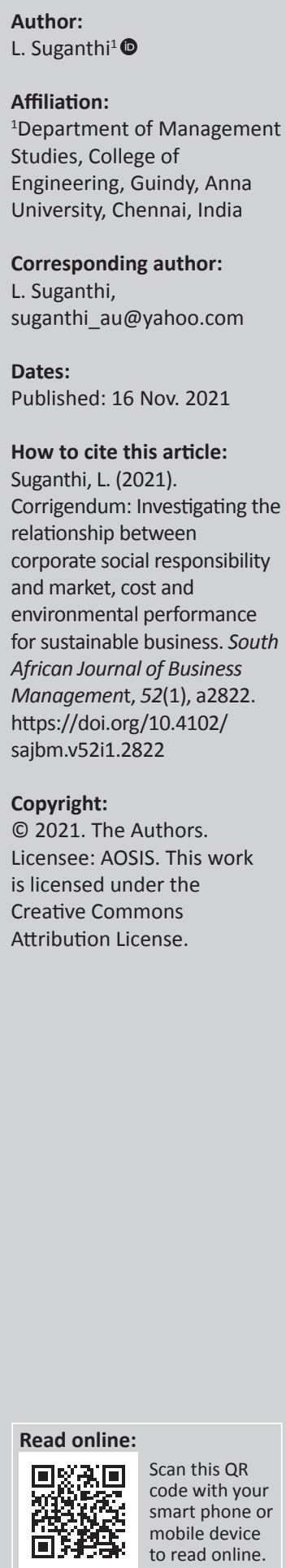

In the version of this article initially published, Suganthi, L. (2020). Investigating the relationship between corporate social responsibility and market, cost and environmental performance for sustainable business. South African Journal of Business Management, 51(1), a1630. https://doi. org $/ 10.4102 /$ sajbm.v51i1.1630, a reference that was referred to in text was omitted in the reference list. The reference is hereby added as:

Farooq, Q., Hao, Y., \& Liu, X. (2019). Understanding corporate social responsibility with cross-cultural differences: A deeper look at religiosity. Corporate Social Responsibility and Environmental Management, 26(4), 965-971. https://doi.org/10.1002/csr.1736

This correction does not alter the study's findings of significance or overall interpretation of the study results. The author apologises for any inconvenience caused. 